\title{
Dimensional stability and strength properties of wood plastic composites produced from sawdust of Cordia alliodora (Ruiz and Pav.)
}

\author{
D. N. Izekor* and M. E. Mordi \\ Department of Forestry and Wildlife, Faculty of Agriculture, University of Benin P.M.B. 1154, Benin City, NIGERIA \\ *Corresponding author. E-mail: david.izekor@uniben.edu
}

Received: July 08, 2014; Revised received: August 23, 2014 ; Accepted: September 16, 2014

\begin{abstract}
This study evaluates the effects of densities and mixing ratio on the physical and mechanical properties of wood plastic composites boards at mixing ratio of $1: 1$ to $1: 1.4$ and nominal densities of $700 \mathrm{~kg} / \mathrm{mm}^{3}$ and $800 \mathrm{~kg} / \mathrm{mm}^{3}$. The quantity of High Density Polyethylene (HDPE) and saw dust used in the production of Wood Plastic Composites (WPCs) was weighed to a nominal density of $700 \mathrm{~kg} / \mathrm{mm}^{3}$ and $800 \mathrm{~kg} / \mathrm{mm}^{3}$. The materials were thoroughly mixed and fed into a neatly primed oil mould with a dimension of $300 \times 300 \times 10 \mathrm{~mm}$. Test samples used for physical and mechanical properties determination were collected from each board produced from the mould. The results showed that WPCs board produced from mixing ratio 1:1 had the highest Modulus of Rupture (MOR) and Modulus of Elasticity (MOE) values of $6.52 \mathrm{~mm} \mathrm{~N}^{-2}$ and $564.95 \mathrm{~mm} \mathrm{~N}^{-2}$ respectively. Water absorption, thickness swelling and linear expansion of WPCs produced from wood/plastic ratio of $1: 1.4$ had the lowest mean values of $6.67,0.83,0.68 \%$ and $21.61,1.33,5.35 \%$ respectively after 2 hours and 24 hours of water immersion test. Analysis of variance carried out at $0.05 \%$ probability level showed that the effect of density and mixing ratio were significant on the physical and mechanical properties of wood plastic composites boards.
\end{abstract}

Keywords: Linear expansion, Modulus of elasticity, Modulus of rupture, Thickness swelling, Water absorption, Wood plastic composites

\section{INTRODUCTION}

Wood plastics composites are materials made from a combination of wood flour, thermoplastic resin and chemical additives (Clemons, 2002). WPCs belong to one of the most dynamic sector in the plastic industries (Rothlin, 2007). Its production and application has increased considerably in recent years. Their properties and environmental advantages have made them a good choice for many applications (Wang and Zang, 2007; Bledzki et al., 2004). WPCs are made by combining wood, thermoplastics polymer, which results in a composites that combine the best properties of both compound (Yang et al., 2007). Virgin thermoplastic such as high and low density polyethylene, polypropylene, polystyrene are the best known WPCs products (Nair et al., 2001; Bengstsson et al., 2005). In addition all recycled plastics which can be melted and processed below the degradation temperature of wood or other lignocellulosic fibres is usually suitable for manufacturing WPCs (Nafaji, 2007). The incorporation of plastic with wood improves the flexural and tensile properties of the resulting composite materials relative to pure plastics (Stark and Rowlands, 2003). Wood plastic composite is one of the engineering wood products that consist primarily of wood and thermoplastic polymers and increase significantly in applications for many purposes. This has become an important and growing segment in the forest product industry (Endra et al., 2012). The main thermoplastic material used in WPCs production are low density polyethylene (LPDE), High Density polyethylene (HPDE), polypropylene (PP), Polyvinylchloride (PVC) and polystyrene (Aina and Fuwape, 2008). These materials are commonly produced with formulation composed of wood waste, synthetic thermoplastic resin and addictives such as fillers, lubricant, inorganic materials, coupling agents, stabilizers and biocides (Aina and Fuwape, 2008).The end uses and choice of materials depends on the manufacturer (Smith, 2001; Wolcott, 2003).

Generally, properties of WPCs depend on various factors, including inherent properties of the constituent materials, interactions among these materials and processing methods. The amount of geometry particle sizes, surface characteristics of the wood component and the interfacial properties between the wood and plastic, influence the mechanical and physical properties of the WPCs (Shebani et al., 2009).

Production of wood plastic composites with the use of HDPE is not yet a common practice. However, the dimensional and strength properties of wood plastic composites with the use of HDPE and tropical wood species such as Gmelina arborea and Terminalia superba have been investigated (Ajigbon and Fuwape, 
2005; Aina and Fuwape, 2008). The objectives of this study was to determine the strength properties and dimensional stability of wood plastic composite board using recycled high density polyethylene at different density levels and mixing ratio. The effects of wood plastics ratio on the physical and mechanical properties of WPCs was also investigated.

\section{MATERIALS AND METHODS}

The study was carried out at the Forest Product Development and Utilization Department of Forestry Research Institute of Nigeria. Saw dust of Cordia alliodora were collected from the sawmill section of the Institute. The sawdust was air-dried to a constant moisture content of $12 \%$ in a controlled laboratory. Thereafter, the sawdust was thoroughly sieved through a 2.00 wire mesh. High density polyethylene (recycled plastic container) used for the study was collected from waste management company in Ibadan, Oyo State, Nigeria.

The quantity of HDPE and saw dust used in the production of WPCs was weighed to a nominal density of $700 \mathrm{~kg} / \mathrm{mm}^{3}$ and $800 \mathrm{~kg} / \mathrm{mm}^{3}$. The materials were thoroughly mixed and fed into a neatly primed oil mould placed between two metal plates with a mould dimension of $300 \times 300 \times 10 \mathrm{~mm}$. The materials were hot pressed at a temperature of $100-120^{\circ} \mathrm{C}$ for 10 minutes at a regular voltage of 240 volts supported with screw jack mounted on the top of the plate to regulate the desired pressure. Plastic boards of thickness $10 \mathrm{~mm}$ were obtained through the stoppers added to the edges of the mould plate. The mould containing the board produced was removed from the plate and allowed to cool before detaching from the mould. The board samples were then trimmed and test samples were collected from each board and tested for both physical properties (water absorption, thickness swelling, linear expansion) and mechanical properties (modulus of rupture and modulus of elasticity). The experiment was conducted as a two factor factorial in a completely randomized designed. Factor $\mathrm{A}$ was the nominal density at the level of $700 \mathrm{~kg} / \mathrm{mm}^{3}$ and $800 \mathrm{~kg} / \mathrm{mm}^{3}$, Factor B was the mixing ratio of the wood/plastic at the level of $1: 1,1: 1.2$, and 1:.4. Each treatment combination has 6 experimental boards and 3 replicates given a total of 18 boards used for the study.

Test for physical properties: Test samples measuring $50 \mathrm{~mm}$ × $50 \mathrm{~mm}$ were used for physical properties determination according to British standard 373 (1989). These properties were water absorption, thickness swelling and linear expansion. Measurements such as thickness (mm), weight (g) and length of the samples were taken prior to test as initial parameters while the final measurement was taken after immersion in water for $2 \mathrm{hrs}$ and 24 hrs respectively. Digital caliper, electronic weighing balance and meter rule was used to measure thickness swelling, weight and linear expansion of the test samples. The different parameters were calculated using the equation: Aina et al. (2014). Water absorption:

WA $(\%)=\left(\mathrm{W}_{2}-\mathrm{W}_{1} / \mathrm{W}_{1}\right) \times 100 \ldots \ldots \ldots \ldots$. Equation 1 Where: $\mathrm{WA}=$ Water Absorption $(\%), \mathrm{W}_{2}=$ final weight after treatment $(\mathrm{g}), \mathrm{W}_{1}=$ initial weight before treatment $(\mathrm{g})$

Thickness swelling:

TS $(\%)=\left(\mathrm{T}_{2}-\mathrm{T}_{1} / \mathrm{T}_{1}\right) \times 100 \ldots \ldots \ldots \ldots \ldots . .$. Equation 2 Where: $\mathrm{TS}(\%)=$ Thickness swelling in percentage, $\mathrm{T}_{2}=$ final thickness after treatment $(\mathrm{mm}), \mathrm{T}_{1}=$ initial thickness before treatment ( $\mathrm{mm})$

\section{Linear expansion:}

$\operatorname{LE}(\%)=\left(\mathrm{L}_{2}-\mathrm{L}_{1} / \mathrm{L}_{1}\right) \times 100 \ldots \ldots \ldots \ldots \ldots . .$. Equation 3 Where: $\mathrm{LE}(\%)=$ Linear expansion $(\%), \mathrm{L}_{2}=$ final length after treatment $(\mathrm{g}), \mathrm{L}_{1}=$ initial length before treatment $(\mathrm{g})$

Mechanical properties: The Modulus of Rupture test was carried out using test samples measuring $50 \mathrm{~mm} \mathrm{x}$ $150 \mathrm{~mm}$ on a Hounsfield Tensiometer Machine according to British Standard 373 (1989). The test samples were supported by two rollers at both ends and loaded at the middle of the span until failure occurs. MOR was calculated from the maximum load at which each sample failed. Modulus of Elasticity (MOE) was calculated using the load to deflection curve plotted on the graph by the Hounsfield Tensiometer testing machine as expressed in the equation below:

MOR $=3 \mathrm{PL} / 2 \mathrm{bd}^{2} \ldots \ldots \ldots \ldots \ldots \ldots \ldots \ldots \ldots \ldots \ldots \ldots \ldots$ Equation 4 Where: $\mathrm{MOR}=$ modulus of rupture $\left(\mathrm{N} \mathrm{mm}^{-2}\right), \mathrm{P}=$ the ultimate failure load $(\mathrm{N}), \mathrm{L}=$ the wood sample span between the machine support $(\mathrm{mm}), \mathrm{b}=$ width of the wood sample $(\mathrm{mm}), \mathrm{d}=$ thickness of the wood sample (mm)

$\mathrm{MOE}=\Delta \mathrm{PL}^{3} / 4 \mathrm{bd}^{3} \Delta \mathrm{s} \ldots \ldots \ldots \ldots \ldots \ldots \ldots \ldots \ldots$ Equation 5 Where: $\mathrm{MOE}=$ modulus of elasticity $\left(\mathrm{N} \mathrm{mm^{-2 }}\right)$, $\mathrm{P}=$ increment in load $(\mathrm{N}), \mathrm{L}=$ the span of the sample between the machine support $(\mathrm{mm}), \mathrm{b}=$ width of the sample $(\mathrm{mm}), \mathrm{d}=$ thickness of the sample $(\mathrm{mm})$, $\Delta \mathrm{s}=$ increment in deflection corresponding to increment in load. Analysis of variance was carried at $0.05 \%$ probability level to estimate the level of significance among the various parameters tested. These parameters were water absorption, thickness swelling, linear expansion, modulus of rupture and modulus of elasticity. Separation of means was carried out using Duncan Multiple Range Test.

\section{RESULTS AND DISCUSSION}

\section{Physical properties:}

Water absorption: The mean values of wood plastic composites for nominal density of $700 \mathrm{~kg} / \mathrm{mm}^{3}$ after 2 hours and 24 hours of water absorption are presented in figs. 1 and 2. The values were 24.2, 9.71, 6.65\% and $33.15,22.48,21.61 \%$ respectively. The mean values obtained for WPCs for nominal density of $800 \mathrm{~kg} / \mathrm{mm}^{3}$ were $10.01,7.47,6.65 \%$ and $28.35,26.9,23.35 \%$ respectively after 2 hours and 24 hours of water 
Table 1. Analysis of variance for physical properties of wood plastic composites after 2 hours and 24 hours immersion test.

\begin{tabular}{|c|c|c|c|c|c|c|c|}
\hline \multirow[t]{2}{*}{ Source of variance } & \multirow[t]{2}{*}{ DF } & \multicolumn{3}{|c|}{ Fcal (2 hrs) } & \multicolumn{3}{|c|}{ Fcal $(24 \mathrm{hrs})$} \\
\hline & & WA & TS & $\mathbf{L E}$ & WA & TS & LE \\
\hline Density & 1 & $0.014 *$ & $0.393^{\mathrm{ns}}$ & $0.079^{\mathrm{ns}}$ & $0.405 \mathrm{~ns}$ & $0.718 \mathrm{~ns}$ & $0.003 *$ \\
\hline Mixing ratio & 2 & $0.002 *$ & $0.852^{\mathrm{ns}}$ & $0.041 *$ & $0.586^{\mathrm{ns}}$ & $0.307^{\mathrm{ns}}$ & $0.084^{\mathrm{ns}}$ \\
\hline D x MRL & 2 & $0.022 *$ & $0.237^{\mathrm{ns}}$ & $0.034 *$ & $0.890^{\mathrm{ns}}$ & $0.735^{\mathrm{ns}}$ & $0.263^{\mathrm{ns}}$ \\
\hline Error & 12 & & & & & & \\
\hline Total & 18 & & & & & & \\
\hline
\end{tabular}

*significant at $(\mathrm{P}<0.05)$ probability level; ns not significant at $(\mathrm{P}<0.05)$ probability level

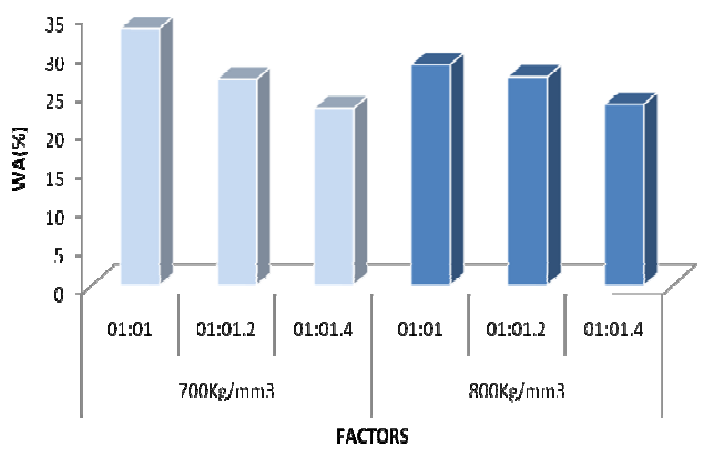

Fig. 1. Effect of densities and mixing ratios on water absorption of WPC after 2 hrs of water immersion test.

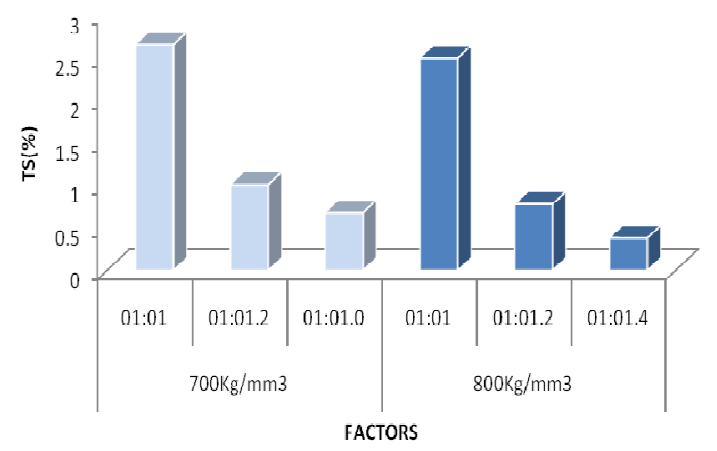

Fig. 3. Effect of densities and mixing ratios on thickness swelling of WPC after 2 hrs of water immersion test.

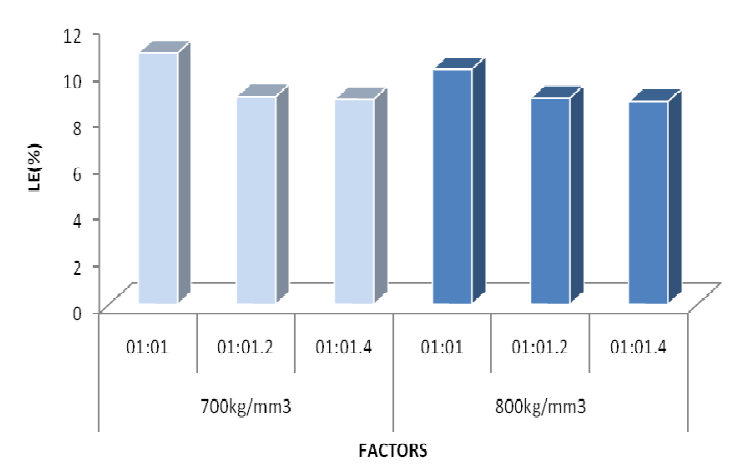

Fig. 5. Effects of densities and mixing ratios on linear expansion of WPC after 2 hrs of water immersion test.

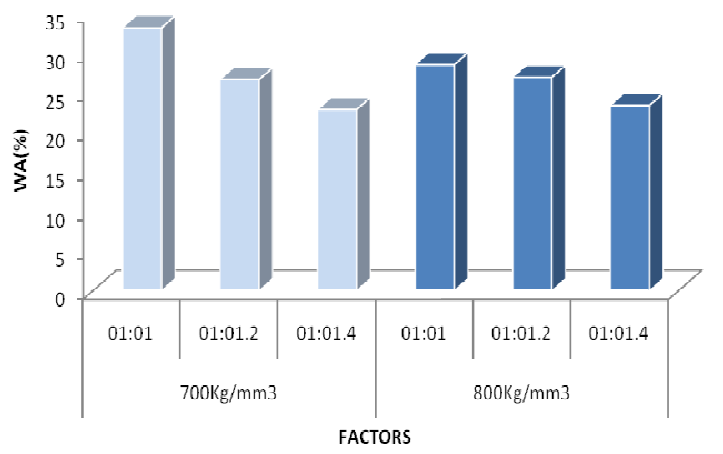

Fig. 2. Effect of densities and mixing ratios on water absorption of WPC after 24 hrs of water immersion test.

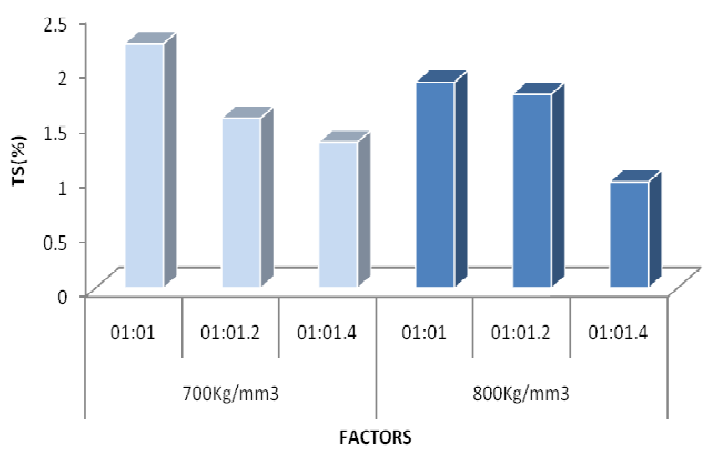

Fig. 4. Effect of densities and mixing ratios on thickness swelling of WPC after 24 hrs of water immersion test.

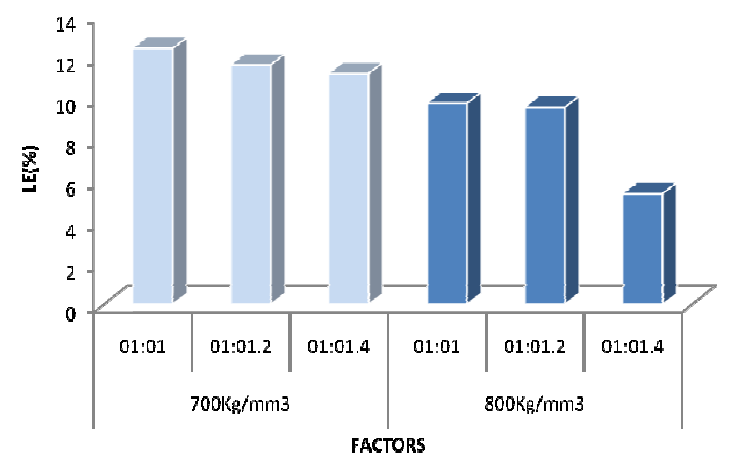

Fig. 6. Effect of densities and mixing ratios on linear expansion of WPC after 24 hrs of water immersion test. 


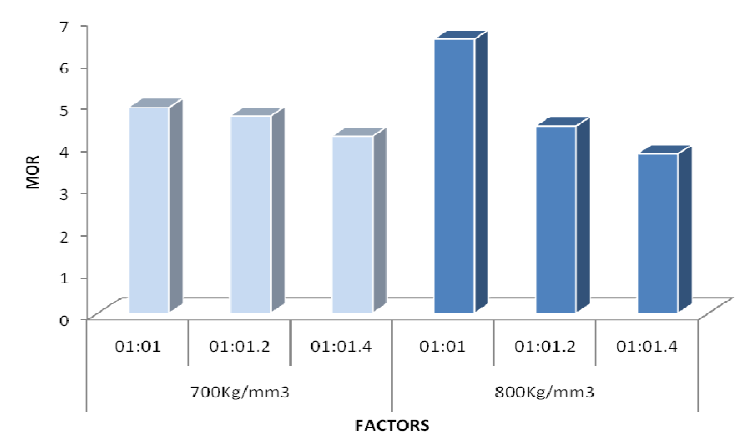

Fig. 7. Effect of densities and mixing ratios on modulus of rupture of WPCs.

Table 2. Analysis of variance for mechanical properties of wood plastic composites.

\begin{tabular}{lccc}
\hline $\begin{array}{l}\text { Source of } \\
\text { variance }\end{array}$ & $\begin{array}{c}\text { Degree of } \\
\text { freedom }\end{array}$ & \multicolumn{2}{c}{ Fcal } \\
\hline Density & 1 & MOE & MOR \\
\hline Mixing ratio & 2 & $0.699^{*}$ & $0.279^{*}$ \\
D *MRL & 2 & $0.584^{\mathrm{ns}}$ & $0.278^{*}$ \\
Error & 12 & $0.254^{\mathrm{ns}}$ & $0.189^{\mathrm{ns}}$ \\
Total & 18 & & \\
\hline
\end{tabular}

*significant $(\mathrm{P}<0.05)$ probability level; $\mathrm{ns}=$ not significant $(\mathrm{P}<0.05)$ probability level

absorption. This shows that the higher the density, the lower the WA values, therefore, as the density and wood/ plastic ratio increases water absorption decreases. The study reveals that as the plastic content in the composites increases, the wood content were more encapsulated by the plastic content which has no affinity for water absorption hence the hydrophobic nature of thermoplastics. The finding from this study is similar to the earlier report by Aina and Fuwape (2008); and Aina et al. (2013) on the properties of wood plastic composites.

The result of analysis of variance for WA shows that both main and two factors interaction were significantly different after 2 hours of immersion test while in 24 hours, the factors were not significantly different at 0.05 level of probability (Table 1). Therefore both density and wood/plastic ratio had positive impact on the water resistance of WPCs.

Thickness swelling: The results of thickness swelling percentage of wood plastic composites for nominal density of $700 \mathrm{~kg} / \mathrm{mm}^{3}$ after 2 hours and 24 hours are presented in figs. 3 and 4 . The values obtained were $2.66,1.01,0.68 \%$ and $2.23,1.55,1.33 \%$ respectively after 2 hours and 24 hours of water immersion test. The mean values obtained for WPCs for nominal density of $800 \mathrm{~kg} / \mathrm{mm}^{3}$ were $2.22,0.84,0.38 \%$ and $1.88,1.77$, $0.97 \%$ respectively after 2 hours and 24 hours of water immersion (figs. 3 and 4). Thickness swelling percentage of wood plastics composites boards produced from nominal densities of $700 \mathrm{~kg} / \mathrm{mm}^{3}$ and $800 \mathrm{~kg} / \mathrm{mm}^{3}$ decreased as the proportion of wood/plastic ratio

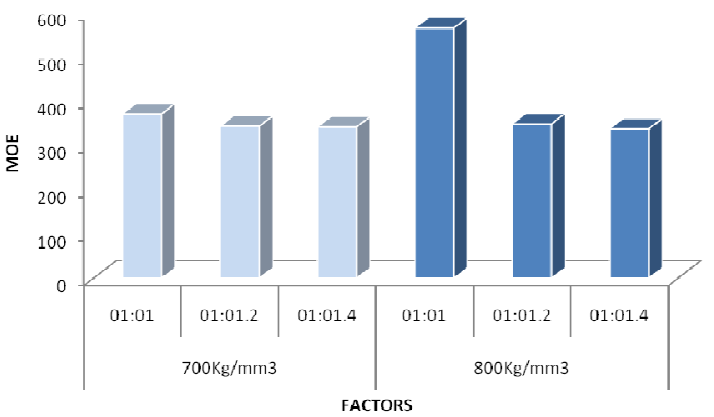

Fig. 8. Effect of densities and mixing ratio on modulus of elasticity of WPCs.

increased. This shows that the more the quantity of the plastic content in the composite, the more resistant the board to water uptake which is proportional to thickness swelling. Similar observations have earlier been reported on the effect of wood/plastic ratio on WPCs (Behzad, 2012 and Aina et al., 2013). As wood is hydrophilic and plastic is hydrophobic, therefore the higher the quantity of plastic and the lesser the quantity of wood, the better the dimensional stability of wood plastic composites. This implies that the more the quantity of the plastic contents in the composite, the more resistant the board to water uptake which is proportional to thickness swelling.

The result of analysis of variance carried out on thickness swelling percentage shows that there was no significant differences between the two factors after 2 hours and 24 hours of water immersion at $0.05 \%$ probability level (Table 1). This means that the interaction between the two main factors does not influence changes in thickness swelling of the boards.

Linear expansion: The mean values of wood plastic composites for nominal density of $700 \mathrm{~kg} / \mathrm{mm}^{3}$ after 2 hours and 24 hours of water absorption are presented in figs. 5 and 6 . The results obtained were 10.82, 8.94, $8.83 \%$ and $11.16,9.73,9.35 \%$ respectively after 2 hours and 24 hours of water immersion test. The mean values obtained for WPCs with nominal density of $800 \mathrm{~kg} / \mathrm{mm}^{3}$ were $10.12,8.88,8.73 \%$ and 12.39 , $11.59,5.35 \%$, respectively after 2 hours and 24 hours of water immersion test (figs. 5 and 6). The results showed that the higher the density, the lower the linear expansion and as the wood/plastic ratio increases, linear expansion decreases. The results also show that linear expansion decreased with increased plastic content which could be attributed to the hydrophobic nature of plastics.

The results of the analysis of variance showed that there was significant difference at $0.05 \%$ probability level in linear expansion after 2 hours of water absorption while there was no significant difference in the interaction between densities and wood/plastic ratios. The interaction between the factors did not have any significant effect on the linear expansion of the WPCs boards produced (Table 1). 


\section{Mechanical properties:}

Modulus of rupture: The mean values obtained for modulus of rupture with nominal density $700 \mathrm{~kg} / \mathrm{mm}^{3}$ and $800 \mathrm{~kg} / \mathrm{mm}^{3}$ are presented in fig. 7 . The values were $4.90,4.61,4.21 \mathrm{~N} \mathrm{~mm}^{-2}$ for nominal density $700 \mathrm{~kg} / \mathrm{mm}^{3}$ and $6.52,4.46,3.79 \mathrm{~N} \mathrm{~mm}^{-2}$, for nominal density $800 \mathrm{~kg} / \mathrm{mm}^{3}$ respectively, MOR values increased with increase in mixing ratio levels and nominal density of $700 \mathrm{~kg} / \mathrm{mm}^{3}$ to $800 \mathrm{~kg} / \mathrm{mm}^{3}$. The strongest boards were produced at the highest levels of wood/plastic ratio and nominal density of $800 \mathrm{~kg} / \mathrm{mm}^{3}$ as they show the greatest improvement at this level. The high proportion of wood/plastic ratio probably contributed to the improved flexural strength of the board. These findings agreed with the previous work reported by Aina and Fuwape (2008). The results of analysis of variance showed that mixing ratio and density has significant effects on MOR of wood plastic composites boards (Table 2).

Modulus of elasticity: The mean values obtained for modulus of elasticity with nominal density $700 \mathrm{~kg} / \mathrm{mm}^{3}$ and $800 \mathrm{~kg} / \mathrm{mm}^{3}$ are presented in fig. 8 . The values were $370.80,342.68,341.03 \mathrm{~N} \mathrm{~mm}^{-2}$ for nominal density $700 \mathrm{~kg} / \mathrm{mm}^{3}$ and $564.95,348.02,337.77 \mathrm{~N} \mathrm{~mm}^{-2}$ for nominal density $800 \mathrm{~kg} / \mathrm{mm}^{3}$, respectively. The stiffness of the board increased with increase in wood/plastic ratio while MOE values were highest in nominal density of $800 \mathrm{~kg} / \mathrm{mm}^{3}$. MOE increased with wood/plastic ratio of $1: 1$ and nominal density of $700 \mathrm{~kg} / \mathrm{mm}^{3}$ to $800 \mathrm{~kg} / \mathrm{mm}^{3}$. These findings are similar to previous work reported on the properties of wood plastic composites (Behzad, 2012). The results of analysis of variance presented in table 2 showed that mixing ratio, density and the two factors interaction has significant effect on modulus of elasticity of WPCs boards at $0.05 \%$ probability level.

\section{Conclusion}

Wood plastic composites were successfully produced at increased sawdust/plastic ratio ranging from 1:1 and 1:1.4 mixing ratio levels. There were observed differences in the physical and mechanical properties of wood plastic composites due to the influence of mixing ratio and densities. The increased sawdust/ plastic ratio between $1: 1$ and $1: 1.4$ mixing ratio and nominal densities of $700 \mathrm{~kg} / \mathrm{mm}^{3}$ and $800 \mathrm{~kg} / \mathrm{mm}^{3}$ had a significant effect on the physical and mechanical properties of wood plastic composites. Therefore, the higher the sawdust/plastic ratio, the higher the dimensional stability of the WPC boards. Also the higher the densities, the better the strength properties leading to higher creep resistance. Thickness swelling, water absorption and linear expansion are a measure of dimensional stability, therefore increased in nominal densities resulted in an increase moisture resistance and ultimately more dimensionally stable boards. WPCs produced with nominal density of $800 \mathrm{~kg} / \mathrm{mm}^{3}$ had better strength characteristics than those produced with nominal density of $700 \mathrm{~kg} / \mathrm{mm}^{3}$ while mixing ratio of 1:1 gave better performance in terms of flexural properties with the highest MOR and MOE of wood plastic composites.

\section{REFERENCES}

Aina, K. S. and Fuwape, J. A. (2008). Effect of weathering on strength properties of wood plastic composites produced from Gmelina arborea. Nigerian Journal of Forestry, 38: $62-73$.

Aina, K. S., Osuntuyi, E. O. and Aruwajoye, A. S. (2013). Comparative studies on physic-mechanical properties of wood plastic composites produced from three indigenous wood species. International journal of science and research. 2 (8): 226 - 230.

Aina, K. S., Osuntuyi, E. O. and Aruwajoye, A. S. (2014). Physico-mechanical properties of wood plastic composites produced from three indigenous wood species. In: Forest and Forest Products; Key to sustainable livelihood (Adedire, M.O; Onyekwelu, J.C; Oke, D.O., Adekunle, V. A. J., Jayeola, O. A. and Oladoye, A. O. Eds). Proceedings of the $4^{\text {th }}$ Biennial Conference of the Forest and Forest Products Society. $22^{\text {nd }}-26^{\text {th }}$ April, 2014. pp. $299-306$.

Ajigbon, A. A and Fuwape, J. A. (2005). Strength and dimensional properties of plastic bonded composite board produced from Afara (Terminalia superba) sawdust. Proc. 1st Annual Conf. Dev. In Agric and Biol. $S c i, 27$ th April, 2005, FUTA, Nigeria.

Behzad, K. (2012). The effect of plastic type and virginity on properties of wood plastic composites. World applied science journal., 17(2):168 - 171.,

Bengtsson, M., Gatenholm, P. And Oksman, K. (2005). The effects of cross linking on the properties of polyethylene/ wood flour Composites Science and Technology 65:1468 - 1479 .

Bledzki, A.K, and Faruk, O. (2004). Extrusion and injection moulded microcellular wood fibre reinforced poly ethylene composites. Cellular Polymer, 23 (4): 211 - 227.

Clemons, C. (2002). Wood plastic composites in the United States; The interfacing of two industries. Forest Product Journal., 52 (6): 10 - 18.

Endra, G., Anom, I. A. and Reinardus, L. C. (2012). Influence of sawdust size and ratio of HDPE waste on the physical properties of wood-plastics composite. International Journal of Basic \& Applied Sciences, 12 (4): $8-42$.

Nafaji, A. (2007). Evaluation of many properties of wood plastic composites made from Ligno cellulosic fibres and recycled HDPE Phd. Dissertation Faculty of Natural Resources Islamic Azad University of Sciences and Research. pp.175.

Nair, K. C. M., Thomas, S. and Groeninck, G. (2001). Thermal and dynamic mechanical analysis of polystyrene composites reinforced with short sisal fibres composites. Science and Technology, 61:2519-2529.

Rothlin, O. (2007) Processing wood-plastic composites places new demands on feeders. Plastic Additives Composites, 9: 36 - 39.

Shebani, A. N., Van Reneenen, A. J. and Meincken, M. (2009). The effect of wood species on the mechanical and thermal properties of wood - LDPE composites. Journal of Composite Materials. 43 (26): 3326 - 3331.

Smith, P. M. (2001). United States wood fibre-plastic 
composites decking market. Proc. $6^{\text {th }}$ International Conference on wood fibre plastic composites Forest Products Society, Madison. pp.13 - 17.

Stark, N. M. and Rowland, R. (2003) Effects of wood fibre characteristic on mechanical properties of wood/ polypropylene composites. Wood and Fiber Science. 35 (2): $167-174$.

Wang, S. and Zhang, J. (2007). Chemical characterization of smoke from the production process of wood plastic composites. Forestry Studies in China. 9: 57-62.

Wolcott, M. P. (2003). Formulation and process development of flat-pressed wood polyethylene composites. Forest Product Journal. 53 (9): $25-32$.

Yang, H. S., Wolcott, M. P., Kim, H. S. and Kim, H. J. (2007). Effect of different compatibilizing agents on the mechanical properties of lignocellulosic material filled polyethylene bio-composites. Composites Structure. 79 (3): $369-375$ 